\title{
AVERAGE PARTICLE VELOCITY IN SOLID-LIQUID TWO-PHASE FLOW THROUGH VERTICAL AND HORIZONTAL TUBES
}

\author{
HiRoYASU OHASHI, TAKUO SUGAWARA, \\ KEN-ICHI KIKUCHI AND MICHIHITO ISÉ \\ Department of Fuel Chemistry, Mining College, \\ Akita University, Akita 010
}

\begin{abstract}
The concentration and velocity profiles of particles were measured for solid-liquid two-phase flow through vertical and horizontal tubes by a conventional photographic method, and through vertical tubes by two newly developed laser methods. Solid materials used were ion-exchange resin particles and glass beads with diameters of 321 to $1840 \mu \mathrm{m}$ and densities of 1190 to 2500 $\mathrm{kg} / \mathrm{m}^{3}$. Tube diameters were $1.92,3.00$, and $5.42 \mathrm{~cm}$.

The average particle velocity, $\bar{U}_{p}$, calculated by the local values of particle concentration and velocity, was correlated with modified Froude number and particle Reynolds number based on the terminal settling velocity in a stagnant fluid with a standard deviation of $5.1 \%$ : for vertical upflow,

$$
\bar{U}_{p} /\left(U_{s}\right)_{a \vee}=\exp \left(0.010 R e_{p}^{0.40}\right)-0.0059 \boldsymbol{R} e_{p}^{0.69}\left[\left(U_{s}\right)_{a v}^{2} /\left\{D_{T} g\left(\rho_{p} / \rho_{w}-1\right)\right\}\right]^{-1 / 2}
$$

for horizontal flow,

$$
\begin{aligned}
& \bar{U}_{p} /\left(U_{s}\right)_{a \vee}=\exp \left(0.016 R \boldsymbol{R}_{p}^{0.36}\right)-0.24 \operatorname{Re}_{p}^{0.22}\left[\left(U_{s}\right)_{\mathrm{a}}^{2} /\left\{D_{r} g\left(\rho_{p} / \rho_{w}-1\right)\right\}\right]^{-1 / 2} \\
& \mathbf{4}<\boldsymbol{R e}_{p}<\mathbf{5 4 0 ,} 2<\left(U_{s}\right)_{\mathrm{av}}^{2} /\left\{D_{T} \boldsymbol{g}\left(\rho_{p} / \rho_{w}-1\right)\right\}<\mathbf{1 2 0}, \boldsymbol{m}_{d}<0.05
\end{aligned}
$$

where $\left(U_{s}\right)_{\mathrm{ar}}$ is average slurry velocity, $D_{T}$ is tube diameter, $\boldsymbol{\rho}_{p}$ and $\boldsymbol{\rho}_{w}$ are particle and liquid density, respectively, and $m_{d}$ is delivered concentration of particles.

The laser methods, one for the local concentration and the other for the local relocity, were successfully adopted as more convenient techniques for getting precise information on the behavior of particles than the conventional photographic method.
\end{abstract}

\section{Introduction}

Information on the local and average values of particle velocity and concentration is essential for investigating the mechanisms of pressure drop and of mass transfer and reaction between particles and liquid in solid-liquid two-phase flow. However, few works have been reported on the velocity and concentration of particles in solid-liquid two-phase flow in a tube. A photographic method ${ }^{2,3,6,9)}$, predominantly used for the local information, requires much time and labor in the analysis of results. But no more convenient method has been brought into use for measuring particle concentration.

As for the local velocity of particles, Yamamoto and Sato $^{11)}$ developed a spatial filtering method with a parallel-slit reticle for fine particles in a moving liquid. The spatial filtering technique has not yet been applied to measure the local velocity of coarse particles $\left(D_{p} \geq\right.$ $200 \mu \mathrm{m})$ in solid-liquid two-phase flow in tubes.

For the average particle velocity, Toda et al. ${ }^{10)}$ used

Received November 29, 1979. Correspondence concerning this article should be addressed to K. Kikuchi. M. Isé is now with Kureha Chem. Ind., Co., Ltd., Tokyo 103. radioactive tracer particles, and Harriott' applied a conductivity method. Ohashi et $a .^{6}{ }^{6}$ determined the average particle velocity considering the local values of particle velocity and concentration. Bhaga and Weber $^{11}$ developed a theoretical analysis for the vertical flow based on the drift-fiux model, and expressed the average particle velocity by means of the difference in two terms including the effect of the distributions of particle concentration. However, they did not correlate the average particle velocity with the various operating parameters. Toda et al. ${ }^{10\rangle}$ tried to correlate the average particle velocity with the operational variables and physical properties. But no successful correlation has yet been established for the average velocity of solids of low density, including resin particles.

In this work, the authors determined the distributions of concentration and velocity of particles for solid-liquid two-phase horizontal flow and vertical upflow using the conventional photographic method; and for vertical upflow using two newly developed laser methods, one for the local concentration of coarse particles and the other for their local velocity. They calculated the average particle velocity from the local 


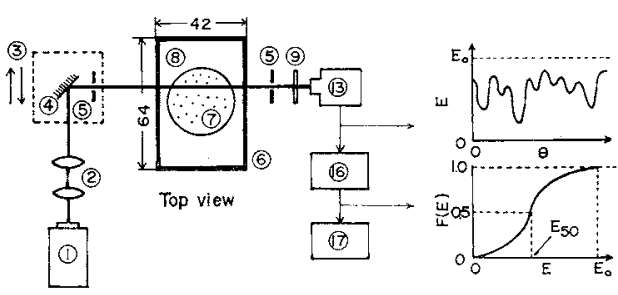

a) Measurement of local concentration of particles with a laser beam (LC method)

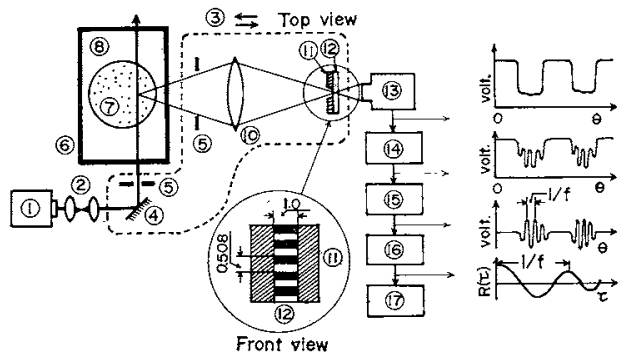

b) Measurement of local velocity of particles with a laser beam (LV method)

(1) $\mathrm{He}-\mathrm{Ne}$ Laser $(20 \mathrm{~mW})$ (10) Lens

(2) Collimator (11) Slit

(3) Optical bench (12) Parallel-slit reticle

(4) Mirror (13) Photomultiplier tube

(5) Aperture (14) Amplifier

(6) Glass box (15) Band pass filter

(7) Glass tube $(30 \mathrm{~mm} \phi)$ (16) Correlator

(8) Water (17) Recorder

(9) Neutral density filter

Fig. 1 Optical arrangement and signal processing system for vertical upflow

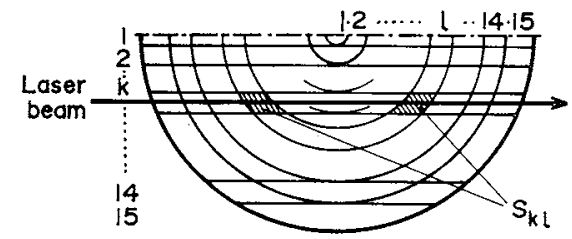

Fig. 2 Cross-section of vertical tube for LC method

concentration and velocity of particles, and correlated it to the operational variables and physical properties with due consideration of the data of Toda et al. ${ }^{10}$, based on the drift-flux model.

\section{Apparatus and Procedure}

\subsection{Measurement of local concentration of particles}

A photographic and a laser method were applied separately to measure the local concentration of particles. The former technique, the same as that used in the studies of the authors ${ }^{6)}$ and Furuta et al..$^{3}$ was adopted for both vertical and horizontal two-phase flow. The latter was for the vertical upflow, being as follows. Figure 1 (a) represents the schematic diagram of optical arrangement and signal processing system with a laser beam (LC method). The output voltage at $50 \%$ of the probability distribution function by the amplitude probability analyzer (10) (TEAC, REAL TIME DIGITAL CORRELATOR, C-120) was taken to be the time-average value, $E_{50}$. The preliminary experiment of changing optical thickness with small stirred vessels revealed that Eq. (1) held between $E_{50}$ and particle concentration, $m$, in the region of particle diameter from 100 to $1000 \mu \mathrm{m}$ and $m$ from 0 to 0.04 :

$$
E_{50} / E_{0}=\exp \left(-\alpha m L_{B}\right)
$$

where $\alpha$ is a constant which depends on the kind and size of particles.

Now, as shown in Fig. 1 (a), the laser beam can be fixed at any position in the plane normal to the flow axis of the tube by translating the optical bench (3) in the direction of the arrows. When the cross-section of the vertical tube is divided as illustrated in Fig. 2, the local time-average particle concentration for $k$-th part, $\left(\bar{m}_{c}\right)_{k}$, is given by Eq. (2):

$$
\left(\bar{m}_{c}\right)_{k}=\sum_{l=k}^{15}\left(m_{c}\right)_{k l} s_{k l} / \sum_{l=k}^{15} s_{k l}
$$

Assuming that the concentration profile of particles is symmetrical about the flow axis, one gets Eq. (3):

$$
\left(m_{c}\right)_{1 l}=\left(m_{c}\right)_{2 l}=\ldots=\left(m_{c}\right)_{k l} \equiv\left(m_{c}\right)_{l}
$$

$\left(m_{c}\right)_{l}$ is obtained by substituting the observed values of $\left(\bar{m}_{c}\right)_{k}$ into Eq. (2) and solving fifteen simultaneous equations with Eq. (3).

\subsection{Measurement of local velocity of particles}

A photographic and a laser method were also adopted separately for measuring the local velocity of particles. The former technique, the same as that used in the previous study ${ }^{6}$, was applied to both vertical and horizontal two-phase flow. The latter was for the vertical upflow. Figure 1 (b) shows the schematic diagram of optical arrangement and signal processing system with a parallel-slit reticle and a laser beam (LV method). The system was a modification of the method of Yamamoto and Sato ${ }^{11)}$. The constant frequency of auto-correlation function for the particles by the real-time digital correlator (16) (TEAC, C-120), $f$, which was independent of the particle concentration of more than $0.02 \mathrm{vol} . \%$ at a given liquid velocity, was transformed to the time-average particle velocity at the measured point, $U_{p}$, through Eq. (4).

$$
U_{p}=f p
$$

where $p$ is the pitch of parallel-slit reticle, $0.508 \mathrm{~mm}$. The radial distribution of particle velocity was obtained by translating the optical bench (3) in the direction of the arrows in Fig. 1 (b).

\section{3 Flow systems and properties of particles}

The vertical pipeline is schematically represented in Fig. 3. Horizontal pipelines are similar to this system. Test tube (4) was made of plexiglass except a part of the vertical tube, including the measuring section, which was a glass tube of the same inside diameter and of thinner wall to minimize the attenuation of light 


\begin{tabular}{|c|c|c|}
\hline \multirow[t]{2}{*}{ Table 1} & \multicolumn{2}{|c|}{ Properties of particles } \\
\hline & $\begin{array}{c}\text { Particle } \\
\text { diameter } \\
{[\mu \mathrm{m}]}\end{array}$ & $\begin{array}{l}\text { Particle } \\
\text { density } \\
{\left[\mathrm{kg} / \mathrm{m}^{3}\right]}\end{array}$ \\
\hline \multirow{5}{*}{ Ion exchange resin } & 321 & 1290 \\
\hline & 567 & 1280 \\
\hline & 790 & 1190 \\
\hline & 805 & 1280 \\
\hline & 807 & 1390 \\
\hline \multirow[t]{2}{*}{ Glass bead } & 1030 & 2500 \\
\hline & 1840 & 2500 \\
\hline Polystyrene & 127 & 1050 \\
\hline
\end{tabular}

intensity through the tube wall. Tube sizes were $30.0 \mathrm{~mm}$ in inside diameter, $8.5 \mathrm{~m}$ in length for vertical flow; $19.2,30.0$ and $54.2 \mathrm{~mm}$ in inside diameter, $10.3 \mathrm{~m}$ in length for horizontal flow. The measuring section was chosen to be $1 \mathrm{~m}$ upstream from the end of the straight test tube.

Particles were continuously injected into the tube by an ejector (3), or by pressurizing with a head tank (11). The injection rate was kept constant within a precision of $5 \%$. The average slurry velocity and delivered concentration of particles were directly determined by sampled volume for an arbitrary time interval. The liquid used was city water. Temperature ranged from 20 to $30^{\circ} \mathrm{C}$.

Properties of particles are shown in Table $\mathbf{1}$.

\section{Calculation of Average Particle Velocity}

The average particle velocity across the cross-section of tube, $\bar{U}_{p}$, was calculated by Eq. $(5)^{6)}$ with the observed local values of $U_{p}$ and $m_{c}$. Details are discussed in the following section.

$$
\bar{U}_{p}=\int_{s} U_{p} m_{c} d s / \int_{s} m_{e} d s
$$

\section{Experimental Results and Discussion}

\section{1 Concentration and velocity profiles of particles}

Figures $\mathbf{4}$ and 5, respectively, show examples of the concentration and velocity profiles of particles in horizontal flow by the photographic method. The local concentration of particles increases downward except in the vicinity of the tube wall. Particle diameter evidently affects the concentration profiles even at moderate average slurry velocity, although particle densities are close to that of water. The delivered particle concentration, $m_{d}$, had no appreciable effect on the local concentration profile of particles. On the other hand, the velocity profiles of particles are similar to that of fluid, which was calculated by $1 / 7$ power law, and seem to be symmetrical about the flow axis, irrespective of the local difference in particle concentration. Figure 6 (a) shows an example of the observed concentration of particles, $\left(\bar{m}_{c}\right)_{k}$, for vertical upflow determined by LC method, where subscript

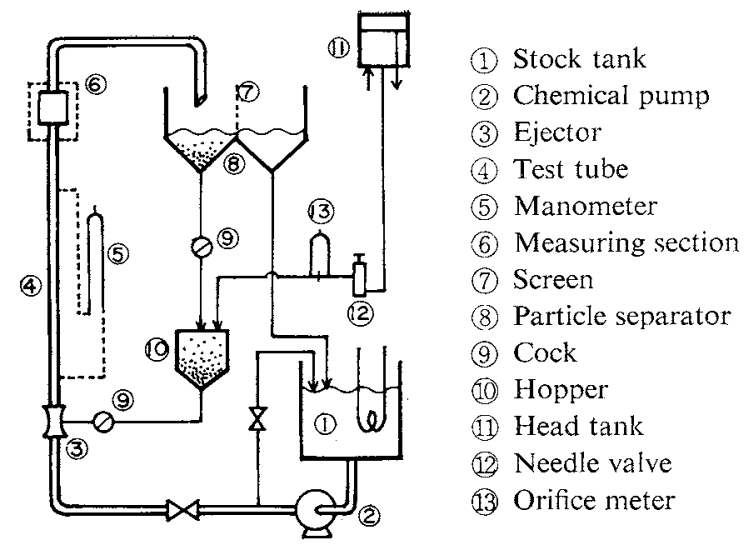

Fig. 3 Vertical flow system

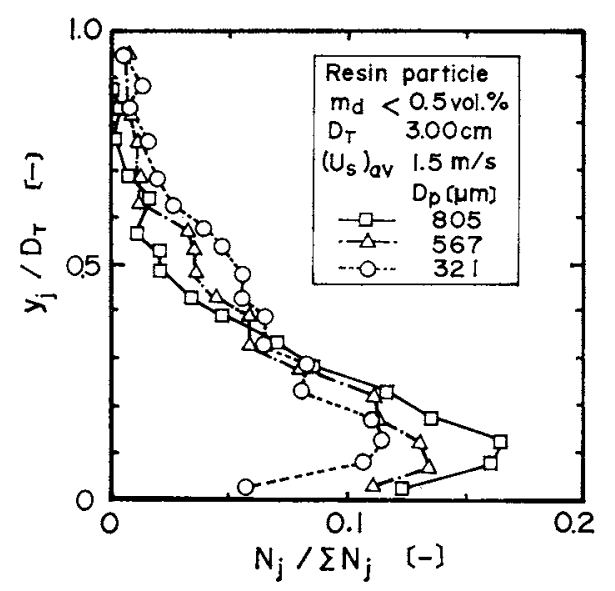

Fig. 4 Concentration profiles of particles in horizontal flow by the photographic method

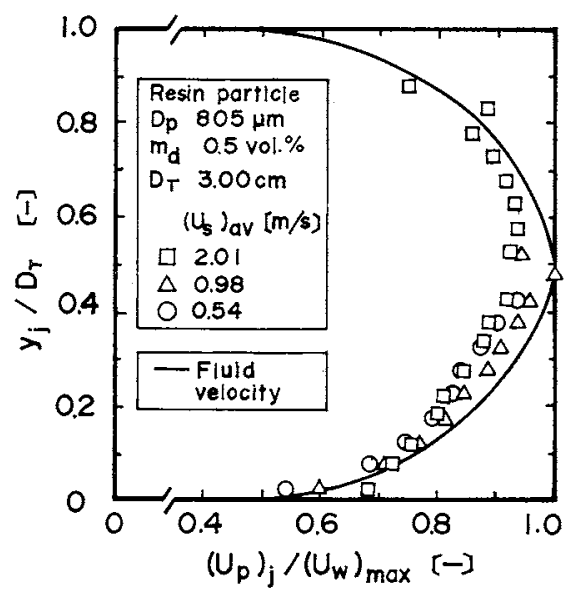

Fig. 5 Velocity profiles of particles in horizontal flow by the photographic method

$k$ denotes $k$-th part in Fig. $2 . \quad\left(\bar{m}_{c}\right)_{k}$ is normalized by the average value across the cross-section of tube, $\left(m_{c}\right)_{\mathrm{a} \vee}$. The calculated concentration by Eqs. (2) and (3) is represented in Fig. 6 (b) for first annular part. The LC method is compared with the photographic one in Fig. 7. Some scatter is inevitable for $m_{c}$ by the latter method because of the limited number of 


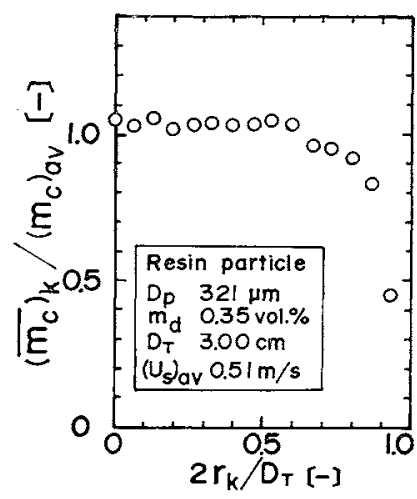

a) Observed at $k$-th part in Fig. 2

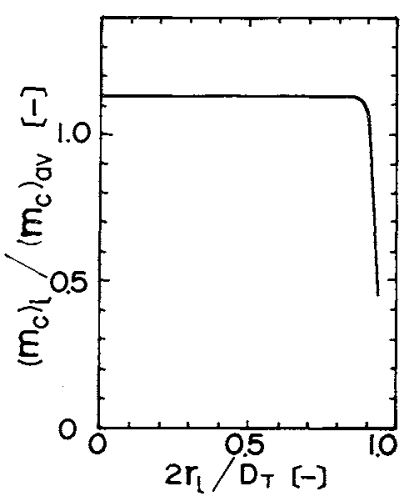

b) Calculated by Eqs. (2) and (3)
Fig. 6 Concentration profile of particles in vertical upflow by LC method

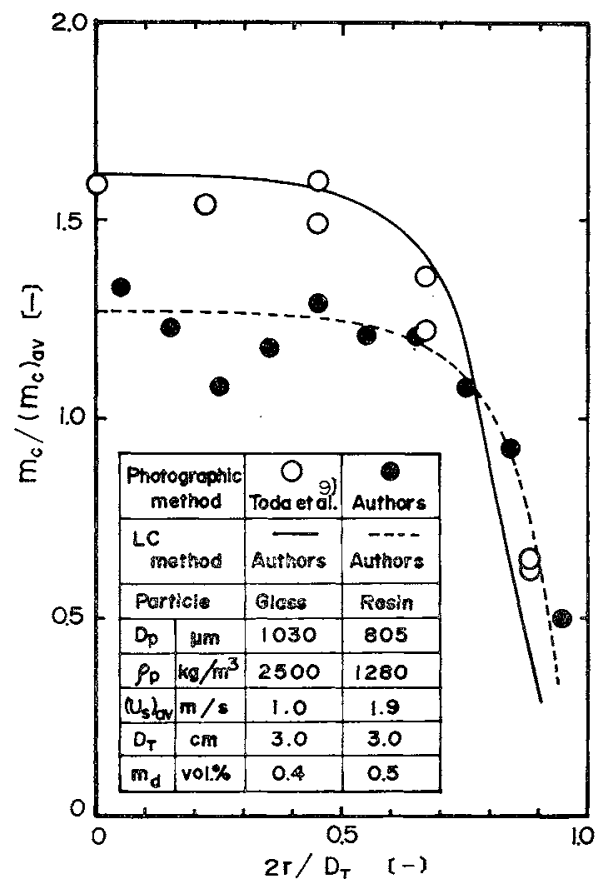

Fig. 7 Comparison of photographic method with LC method in vertical upflow

samples. Consequently, LC method would provide a more convenient tool for getting precise information on the local concentration of particles in vertical flow from the viewpoint of economy of time and labor. Figure 8 shows the drastic effect of average slurry velocity on the concentration profiles of particles. The tendency of change in profiles coincides with that reported by Furuta et $a l^{31}$

Figure 9 shows examples of the velocity profiles of particles and liquid in vertical upflow by LV method. Polystyrene particles were used as a tracer to measure liquid velocity, the profile of which agreed with $1 / 7$ power law. It made LV method permissible for the determination of the local velocity of particles. The LV method would be more expedient than the photo-

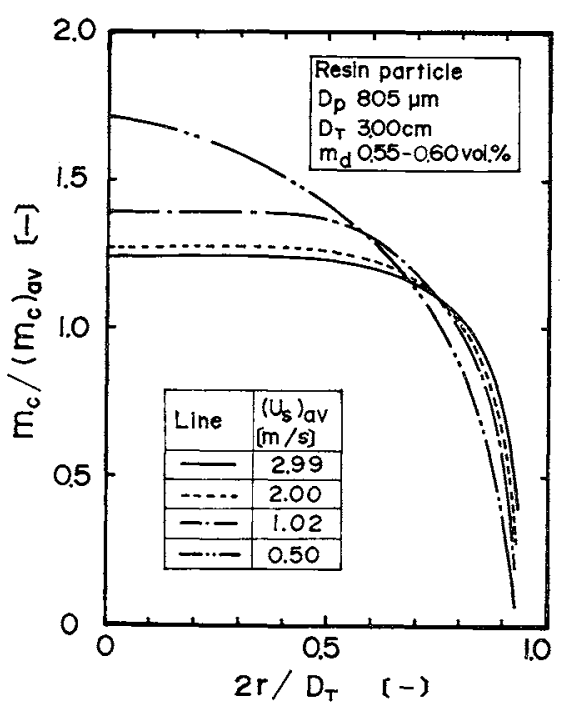

Fig. 8 Effect of average slurry velocity on concentration profiles of particles in vertical upflow

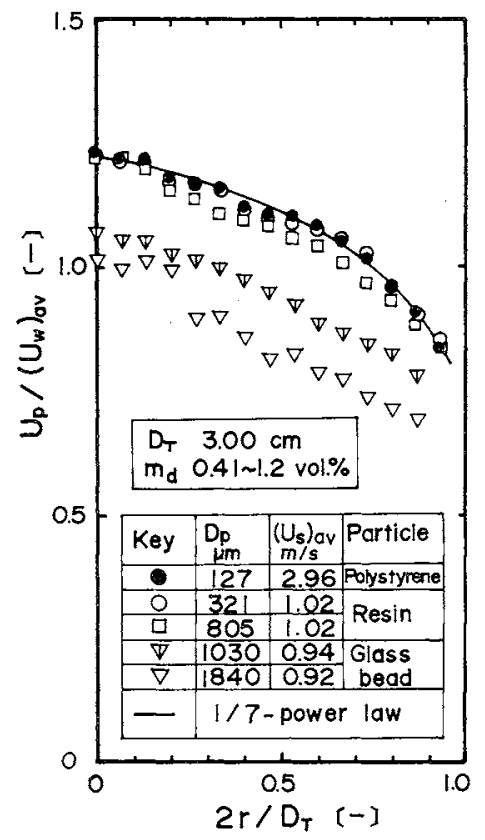

Fig. 9 Velocity profiles of particles and liquid in vertical upflow by $L V$ method

graphic one from the standpoint of precision and economy of time and labor. The difference between the local velocity of particles and that of liquid was of the order of terminal settling velocity in a stagnant liquid as indicated by Kada and Hanratty ${ }^{5}$.

\section{2 Average particle velocity}

The average particle velocity, $\bar{U}_{p}$, was calculated by Eq. (5) with the following assumptions: (1) the concentration profile of particles was symmetrical about the flow axis for vertical upflow, and flat for horizontal flow; (2) the velocity profile of particles was balanced about the flow axis for both vertical and horizontal flow. Validity of the assumptions, (1) and (2) was 


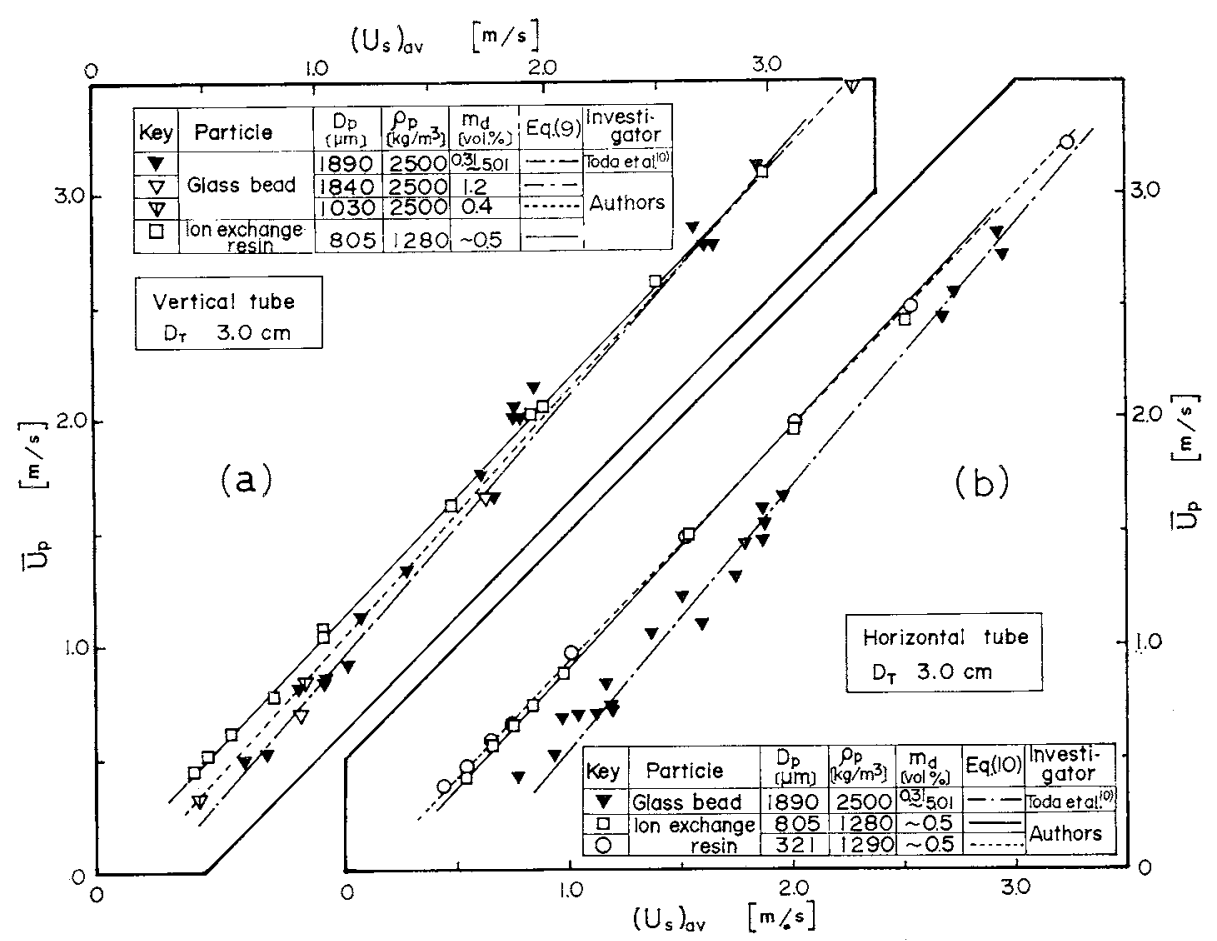

Fig. 10 Correlation of $\vec{U}_{p}$ with $\left(U_{s}\right)_{\mathrm{a}}$ in vertical upflow (a) and in horizontal flow (b)

confirmed by the following material balance for the particles.

$$
\frac{\bar{U}_{p}}{\left(\bar{U}_{s}\right)_{\mathrm{av}}}=K_{c}-\frac{K_{k}\left(U_{p}\right)_{t}}{\left(U_{s}\right)_{\mathrm{av}}}
$$

$$
\bar{U}_{p}\left(m_{c}\right)_{\mathrm{av}}=\left(U_{s}\right)_{\mathrm{a} v} m_{d}
$$

It held within a precision of $10 \%$ under the experimental conditions studied.

Figure 10 (a) shows examples of the relation between the average particle velocity, $\bar{U}_{p}$, and the average slurry velocity, $\left(U_{s}\right)_{\mathrm{av}}$, in the vertical upflow including the data of Toda et al. for glass beads ${ }^{10)}$. They used the radioactive tracer method, in which the average particle velocity was defined as 0.5 of the cumulative velocity distribution function. Their definition may be taken to be equivalent to the definition by Eq. (5) since their data are almost the same as the calculated values by Eq. (5) under the same slurry-velocity conditions. The figure shows that the positive or negative difference between $\vec{U}_{p}$ and $\left(U_{s}\right)_{\mathrm{av}}$ becomes greater as the diameter and the density of particles get bigger, while the delivered particle concentration has no influence under the experimental conditions studied. $\bar{U}_{p}$ is slightly larger than $\left(U_{s}\right)_{\mathfrak{a}}$ at high velocity, the result mainly of the change in concentration profile of particles with increasing $\left(U_{s}\right)_{\mathrm{av}}$ as shown in Fig. 8. Figure 10 (b) shows examples for horizontal flow, also including the data of Toda et al. ${ }^{10)} . \bar{U}_{p}$ is always smaller than $\left(U_{s}\right)_{\mathrm{av}}$ in horizontal flow.

\section{3 Correlation of average particle velocity}

$\bar{U}_{p}$ is affected by the distributions of the particle velocity, $U_{p}$, and of the particle concentration, $m_{c}$. Bhaga and Weber ${ }^{1 /}$ gave the following theoretical equation for vertical flow based on the drift-flux model, considering the distributions of $m_{c}$ and $U_{p}$.

where $K_{c}$ is "the distribution parameter" and $K_{k}$ is "the terminal velocity coefficient". Both constants may be mainly dependent on the distribution of $m_{c}$. Furuta et al. ${ }^{3}{ }^{3}$ concluded that the distribution of $m_{\mathrm{c}}$ for vertical flow depended on particle Reynolds number based on the terminal settling velocity in a stagnant fluid, $R e_{p}$. Toda et $a l .{ }^{8}$ reported that the dimensionless relative velocity between a single particle and fluid for vertical upflow was a function of modified Froude number. To determine the dependency of each term of Eq. (7) on the various operating parameters and physical properties, the authors assumed that the particle velocity for vertical upflow would be expressed by the following equation including $R e_{y}$ and modified Froude number, $\left(U_{s}\right)_{\mathrm{av}}^{2} / D_{T} g\left(\rho_{p} / \rho_{w}-1\right)$ :

$$
\left(\bar{U}_{p}\right)_{\mathrm{av}}=\exp \left(K_{1} \operatorname{Re}_{p}^{K_{1}{ }^{\prime}}\right)-K_{2} \operatorname{Re}_{p}^{K_{2}{ }^{\prime}}\left\{\frac{\left(U_{s}\right)_{\mathrm{av}}^{2}}{D_{T} g\left(\rho_{p} / \rho_{w}-1\right)}\right\}^{-1 / 2}
$$

where the power of modified Froude number was fixed to be $-1 / 2$ on the basis of the single-particle study by Toda et $a l^{8}{ }^{8}$ : it might be permissible to evaluate the two-phase flow characteristics in the region of dilute particle concentration by use of singleparticle phenomena. $m_{d}$ was not included in the correlating parameters in Eq. (8) since it had no influence under the experimental conditions of dilute particle concentrations shown in Fig. 10 (a). Equation (8) was also assumed to apply to correlate the particle velocity for horizontal flow. By using all of the data, Eqs. (9) and (10) were obtained for vertical upflow and 


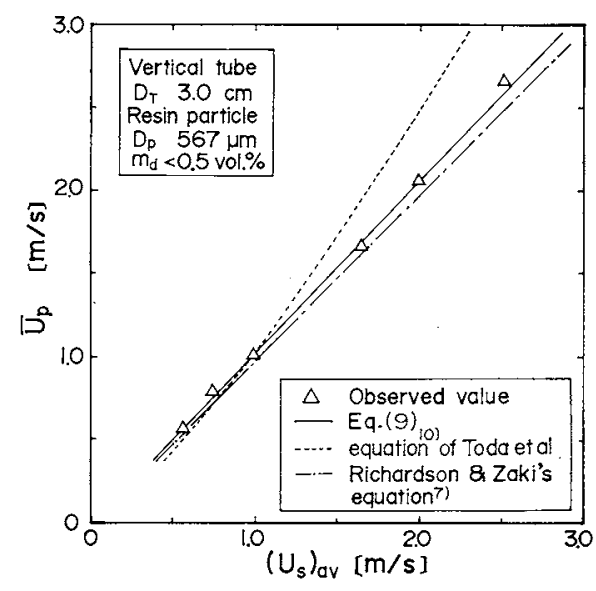

Fig. 11 Comparison between observed values and calculated ones by Eq. (9) and previous equations for vertical upflow

for horizontal flow, respectively, with a standard deviation of $5.1 \%$.

For vertical upflow,

$$
\begin{aligned}
\bar{U}_{p} /\left(U_{s}\right)_{\mathrm{av}}= & \exp \left(0.010 R e_{p}^{0.40}\right)-0.0059 R e_{p}^{0.69} \\
& \times\left[\left(U_{s}\right)_{\mathrm{av}}^{2} /\left\{D_{T} g\left(\rho_{p} / \rho_{w}-1\right)\right\}\right]^{-1 / 2}
\end{aligned}
$$

For horizontal flow,

$$
\begin{aligned}
& \bar{U}_{p} /\left(U_{s}\right)_{\mathrm{av}}= \exp \left(0.016 R e_{p}^{0.36}\right)-0.24 R e_{p}^{0.22} \\
& \times\left[\left(U_{s}\right)_{\mathrm{a}}^{2} /\left\{D_{T} g\left(\rho_{p} / \rho_{w}-1\right)\right\}\right]^{-1 / 2} \\
& 4<R e_{p}<540,2<\frac{\left(U_{s}\right)_{\mathrm{av}}^{2}}{D_{T} g\left(\rho_{p} / \rho_{w}-1\right)}<120, m_{d}<0.05
\end{aligned}
$$

Examples of calculated lines of $\bar{U}_{p}$ are shown for each particle in Figs. 10 (a) and (b).

Figure 11 shows the comparison of Eq. (9) with the observed values for the particle of low density and with the previous empirical equations ${ }^{7,10}$ ) for vertical twophase upflow. The equation ${ }^{10}$ of Toda et al. deviates remarkably from the observed values at high velocity. Richardson and Zaki's equation ${ }^{7)}$, obtained by measuring the relative velocity between particles and fluid in sedimentation and fluidization, slightly falls behind the observed values. The same tendency of deviation was observed for horizontal two-phase flow.

\section{Concluding Remarks}

The concentration and velocity profiles of particles were measured for solid-liquid two-phase flow in vertical and horizontal tubes by a photographic method and two laser methods. The laser methods, one for the local concentration ( $\mathrm{LC}$ method) and the other for the local velocity (LV method), gave more precise values than the photographic method.

The average particle velocities across the crosssection of tubes were satisfactorily correlated with a standard deviation of $5.1 \%$ as follows.

For vertical upflow,

$$
\begin{aligned}
\bar{U}_{p} /\left(U_{s}\right)_{\mathrm{av}}= & \exp \left(0.010 R e_{p}^{0.40}\right)-0.0059 R e_{p}^{0.69} \\
& \times\left[\left(U_{s}\right)_{\mathrm{av}}^{2} /\left\{D_{T} g\left(\rho_{p} / \rho_{w}-1\right)\right\}\right]^{-1 / 2}
\end{aligned}
$$

and for horizontal flow,

$$
\begin{aligned}
& \bar{U}_{p} /\left(U_{s}\right)_{\mathrm{av}}= \exp \left(0.016 R e_{p}^{0.36}\right)-0.24 R e_{p}^{0.22} \\
& \times\left[\left(U_{s}\right)_{\mathrm{av}}^{2} /\left\{D_{T} g\left(\rho_{p} / \rho_{w}-1\right)\right\}\right]^{-1 / 2} \\
& 4<R e_{p}<540,2<\frac{\left(U_{s}\right)_{\mathrm{av}}^{2}}{D_{T} g\left(\rho_{p} / \rho_{w}-1\right)}<120, m_{d}<0.05
\end{aligned}
$$

\section{Acknowledgment}

The authors would like to thank Mitsubishi Chemical Industries Ltd. for its financial assistance and offer of ion-exchange resin particles. They are also grateful to Professor K. Yamamoto and Mr. Y. Sato at the Department of Chemical Engineering, Yokohama National University, for their information on the measuring technique with a laser beam. The assistance of student colleagues (Messrs. M. Takeda, T. Kawazoko, T. Obara, T. Miyano, K. Suzuki, H. Abe, H. Mabusé, Y. Hamano, K. Hatakeyama, M. Yoneya, and T. Sakuta) is also appreciated.

\section{Nomenclature}

$D \quad=$ diameter [m]

$E_{0} \quad=$ voltage in absence of particle [V]

$E_{50} \quad=$ time-average voltage [V]

$F(E) \quad=$ probability distribution function $\quad[-]$

$f \quad=$ frequency $\quad[1 / \mathrm{s}]$

$g \quad=$ acceleration of gravity $\quad\left[\mathrm{m} / \mathrm{s}^{2}\right]$

$K_{1}, K_{1}^{\prime} \quad=$ constants $\quad$ [-]

$K_{2}, K_{2}{ }^{\prime} \quad=$ light path length [m]

$m \quad=$ particle concentration [volume fraction]

$m_{c} \quad=$ particle concentration in tube [volume fraction]

$\left(m_{c}\right)_{\mathrm{av}} \quad=$ average particle concentration across cross-section of tube $=\int_{s} m_{c} d s / \int_{s} d s$

[volume fraction]

$\left(\bar{m}_{c}\right)_{k} \quad=$ average concentration of particles defined by Eq. (2) [volume fraction]

$\left(m_{c}\right)_{l} \quad=$ local concentration of particles defined by Eq. (3) [volume fraction]

$=$ delivered concentration of particles

[volume fraction]

$N=$ number of particles per unit tube volume $\left[1 / \mathrm{m}^{3}\right]$

$p \quad=$ pitch $[\mathrm{m}]$

$R e_{p} \quad=$ particle Reynolds number based on terminal settling velocity in stagnant fluid $=D_{p}\left(U_{p}\right)_{t} / \nu$

$=$ autocorrelation function

$r \quad=$ radial distance from center of tube [m]

$s \quad=$ cross-sectional area $\quad\left[\mathrm{m}^{2}\right]$

$U_{p} \quad=$ particle velocity $\quad[\mathrm{m} / \mathrm{s}]$

$\bar{U}_{p} \quad=$ average velocity of particles defined by Eq. (5)

$[\mathrm{m} / \mathrm{s}]$

$\left(U_{p}\right)_{t} \quad=$ terminal settling velocity of particles in stagnant fluid

$U_{s} \quad=$ slurry velocity $=U_{p} m_{c}+U_{w}\left(1-m_{c}\right) \quad[\mathrm{m} / \mathrm{s}]$

$\left(U_{s}\right)_{\mathrm{a} \vee} \quad=$ average slurry velocity $=V_{s} /\left(\pi D_{T}^{2} / 4\right)$

$U_{w} \quad=$ liquid velocity

$V_{s} \quad=$ volumetric slurry velocity

$y=$ radial distance from tube wall $\quad$ [m]

$[\mathrm{m} / \mathrm{s}]$

$[\mathrm{m} / \mathrm{s}]$

$\left[\mathrm{m}^{3} / \mathrm{s}\right]$

$\alpha \quad=$ constant $\quad[1 / \mathrm{m}]$

$\beta, \gamma=$ constants $\quad[-]$ 
$=$ kinematic viscosity

〈Subscripts〉

$$
\begin{array}{ll}
j & =1,2 \ldots, 20 ; j \text {-th part of cross-section } \\
k l & =k l \text {-th part of cross-section } \\
p & =\text { particle } \\
T & =\text { tube } \\
W & =\text { liquid }
\end{array}
$$

\section{Literature Cited}

1) Bhaga, D. and M. E. Werber: Can. J. Chem. Eng., 50, 323 (1972).

2) Furuta, T., K. Nakamae, S. Tsujimoto, M. Okazaki and R. Toei: Preprint of the 8th Autumn Meeting of The Soc. of Chem. Engrs., Japan, p. 244 (1974).

3) Furuta, T., S. Tsujimoto, M. Toshima, M. Okazaki and R. Toei: Kagaku Kogaku Ronbunshu, 4, 105 (1978).

\footnotetext{
4) Harriott, P.: AIChE J., 8, 101 (1962).

5) Kada, H. and T. J. Hanratty: ibid., 6, 624 (1960).

6) Ohashi, H., T. Sugawara, K. Kikuchi and T. Henmi: $J$. Chem. Eng. Japan, 12, 190 (1979).

7) Richardson, J. F. and W. N. Zaki: Trans. Instn. Chem. Engrs., 32, 35 (1954)

8) Toda, M., H. Konno, S. Saito and S. Maeda: Kagaku Kögaku, 33, 67 (1969).

9) Toda, M., T. Shimizu, S. Saito and S. Maeda: Preprint of the 37th Annual Meeting of The Soc. of Chem. Engrs., Japan, p. 202 (1972).

10) Toda, M., T. Ishikawa, S. Saito and S. Maeda: J. Chem. Eng. Japan, 6, 140 (1973).

11) Yamamoto, K. and Y. Sato: Preprint of the 41st Annual Meeting of The Soc. of Chem. Engrs., Japan, p. 120 (1976).

(In part presented at Akita Meeting (Akita, Aug., 1974), the 40th Annual Meeting (Nagoya, April, 1975), Hokkaido Meeting (Muroran, July, 1975), and Tohoku Meeting (Akita, Oct., 1978) of The Soc. of Chem. Engrs., Japan.)
}

\title{
DEVELOPING AND FULLY DEVELOPED TURBULENT FLOW THROUGH ANNULI
}

\author{
R. P. SINGH, K. K. NIGAM AND P. MISHRA \\ Department of Chemical Engineering, Institute of Technology, \\ Banaras Hindu University, Varanasi-221005 India
}

\begin{abstract}
Turbulent flow velocity profiles for the inner and outer flow regions of annuli are proposed. Theoretical expressions for friction factors and entrance region pressure drops are developed and are further extended to the limiting cases of pipes and parallel plates. Experimental data are found to be in good agreement with theoretical results.
\end{abstract}

\section{Introduction}

Study of turbulent flow through an annulus primarily requires a knowledge of the velocity profile, which has been a subject of discussion for the last three decades. A number of investigators ${ }^{1-7,11)}$ have presented extensive work on the subject, but the discrepancy between experimental and theoretical results is still to be explained.

Lundgren $e t a l^{8)}$ presented a method for estimation of entrance loss in laminar flow through a channel of

Received February 4, 1980. Correspondence conceruing this article should be addressed to P. Mishra. R. P. Singh is at Dept. of Chem. Eng., B. I. T., Sindri, Dhanbad: and K. K. Nigam is at Dept. of Chem. Eng., H. B. T. I, Kanpur. arbitrary cross-section. The investigation made by Okiishi and Serovy ${ }^{10}$ shows the dependence of flow development on the geometry of the entrance. Thorpe $^{12,13)}$ made extensive review of the previous investigations on turbulent flow through annuli and showed that modified logarithmic velocity profiles provide a simple, accurate relationship for annular friction coefficient. The purpose of the present investigation is to propose an appropriate turbulent flow velocity profile and relationships for friction factor in an annulus. A method to predict the entrance region pressure drop in an annulus, which is an important consideration in the design of heat exchangers, is also proposed. 